\title{
Effect of boiling point rankings and feed locations on the applicability of reactive distillation to quaternary systems
}

DOI:

10.1016/j.cherd.2019.03.014

\section{Document Version}

Accepted author manuscript

Link to publication record in Manchester Research Explorer

\section{Citation for published version (APA):}

Muthia, R., van der Ham, A. G. J., Jobson, M., \& Kiss, A. (2019). Effect of boiling point rankings and feed locations on the applicability of reactive distillation to quaternary systems. Chemical Engineering Research \& Design. https://doi.org/10.1016/j.cherd.2019.03.014

\section{Published in:}

Chemical Engineering Research \& Design

\section{Citing this paper}

Please note that where the full-text provided on Manchester Research Explorer is the Author Accepted Manuscript or Proof version this may differ from the final Published version. If citing, it is advised that you check and use the publisher's definitive version.

\section{General rights}

Copyright and moral rights for the publications made accessible in the Research Explorer are retained by the authors and/or other copyright owners and it is a condition of accessing publications that users recognise and abide by the legal requirements associated with these rights.

\section{Takedown policy}

If you believe that this document breaches copyright please refer to the University of Manchester's Takedown Procedures [http://man.ac.uk/04Y6Bo] or contact uml.scholarlycommunications@manchester.ac.uk providing relevant details, so we can investigate your claim.

\section{OPEN ACCESS}




\title{
Effect of boiling point rankings and feed locations on the applicability of reactive distillation to quaternary systems
}

\author{
Rahma Muthia', Aloijsius G. J. van der Ham ${ }^{2}$, Megan Jobson ${ }^{1}$, Anton A. Kiss ${ }^{1,2 *}$ \\ ${ }^{1}$ School of Chemical Engineering and Analytical Science, The University of Manchester, \\ Sackville Street, Manchester, M13 9PL, United Kingdom \\ ${ }^{2}$ Sustainable Process Technology Group, Faculty of Science and Technology, University of \\ Twente, PO Box 217, 7500 AE Enschede, The Netherlands \\ *Corresponding author: TonyKiss@gmail.com, Tel: +44 1613068759
}

\section{Keywords}

Reactive distillation, mapping method, applicability graph, quaternary systems

\section{Highlights}

- Insights into reactive distillation (RD) design and techno-economic applicability

- Conceptual process design and preliminary economic ranking of RD processes

- Influence of feed locations on the performance of reactive distillation systems

- Effect of boiling point order on the applicability of RD to quaternary systems

\section{Abstract}

Reactive distillation (RD) offers major benefits such as costs reduction and energy saving, but the understanding and design of $\mathrm{RD}$ processes usually demand complex tasks that include extensive studies and rigorous simulations. To reduce this complexity and the time required, this study applies a novel mapping method to quickly provide insights into the RD applicability to reversible quaternary systems $(\mathrm{A}+\mathrm{B} \rightleftharpoons \mathrm{C}+\mathrm{D})$. Generic cases are used to produce applicability graphs (i.e. plots of reflux ratio vs number of theoretical stages) and multiple RD column configurations. The systems are assumed to have ideal properties and fixed key parameters (i.e. relative volatilities and chemical equilibrium constants). This study focuses on quaternary reactions considering different boiling point rankings and feed locations. Using the mapping method, quick results are achievable regarding the preliminary economic ranking of RD processes, and the optimal feed locations with reduced energy requirement (i.e. lower reflux ratio). Ultimately, this study provides a much better understanding of the effect of boiling point orders and feed locations on the RD applicability and conceptual design, being a valuable tool in early techno-economic evaluations. 


\section{1. Introduction}

2 Reactive distillation (RD) is a process intensification technique that allows simultaneous separation to take place when chemical reaction occurs. RD gives benefits to equilibriumlimited reactions by pulling the chemical equilibrium towards complete conversion and allowing high selectivity (e.g. avoiding potential consecutive reactions) due to the continuous removal of products from the RD column (Baur et al., 2000). Among others, RD offers great advantages in costs reduction by simplifying complex processes and integrating the reaction and separation functions into a single unit with reduced requirements (Kiss, 2018). The use of exothermic heat of reaction to drive the liquid vaporization reduces the energy requirement (Kaur and Sangal, 2017). There are also health, safety and environmental improvements mainly because of less emissions from plants, lower levels of reactive hold-up and decreased risks of runaway reactions (Taylor and Krishna, 2000; Shah et al., 2012).

The commercialization of reactive distillation has expanded for over 30 years (Stankiewicz, 2003). The most well-known RD process is in the methyl acetate production via esterification, which has been established since 1984 by Eastman Kodak Company (Agreda et al., 1990). The syntheses of ethers, i.e. methyl tert-butyl ether, ethyl tert-butyl ether and tert-amyl methyl ether, are other remarkable examples where RD technology is applied (Sharma and Mahajani, 2002). Furthermore, the implementation of RD is very appealing to other reactions involving reversible quaternary systems $(\mathrm{A}+\mathrm{B} \rightleftharpoons \mathrm{C}+\mathrm{D})$ and ternary systems $(\mathrm{A}+\mathrm{B} \rightleftharpoons \mathrm{C}$ and $\mathrm{A} \rightleftharpoons \mathrm{B}+$ C). Some examples include the hydration of cyclohexene to obtain cyclohexanol (Chen et al., 2014), dehydration of glycerol to acetol (Chiu et al., 2006), isoamyl acetate production via esterification of isoamyl alcohol and acetic acid (González et al., 2017) and diethyl carbonate synthesis via trans-esterification of propylene carbonate and ethanol (Wang et al., 2014).

Studies related to RD technology provide various methods to design and control the column operation, specify and modify its physical structures and/or evaluate the economic aspect. For example, a set of equations can be used to calculate the minimum reflux ratio $\left(R R_{\min }\right)$ for both single- and double-feeds RD columns (Barbosa and Doherty, 1988a; Barbosa and Doherty, 1988b). The location of reactive zone in binary reactions can be visualized by using the McCabe-Thiele and Ponchon Savarit methods (Lee et al., 2000). Other studies determined heuristic approaches, by considering basic knowledge and industrial experience, to specify the operating conditions and the physical aspects of RD (Subawalla and Fair, 1999). Other RD design methods have been also reported in literature (Buzad and Doherty, 1994; Ciric and Gu, 1994; Almeida-Rivera et al., 2004; Groemping et al., 2004; Thery et al., 2005; Jantharasuk et al., 2011). However, in contrast to much information available, the complexity of designing 
1 and understanding RD processes remained a strong barrier that has hindered the rapid 2 commercialization of RD for over 15 years (Chen et al., 2000; Malone and Doherty, 2000; 3 Harmsen, 2007; Segovia-Hernández et al., 2015; Li et al., 2016). In other words, simplicity is

4 strongly needed in the assessment of RD design at early stages of industrial R\&D. The present study aims to provide insights into RD processes by using a mapping method that was initially developed to quickly assess the applicability of RD based on pre-defined maps (i.e. applicability graphs) obtained from generic cases (Muthia et al., 2018). In that initial work, we validated the approach using two case studies, i.e. hydrolysis of methyl lactate and transesterification of methyl benzoate and benzyl alcohol, and showed that one can successfully use the generic cases to predict the applicability of RD to real systems. The following assumptions for the generic cases are applied in this study: ideal thermodynamics (neither azeotropes nor liquid split); fixed values of key parameters, i.e. relative volatility $(\alpha)$ and chemical equilibrium constant $\left(\mathrm{K}_{\mathrm{eq}}\right)$; and vapor-liquid and chemical equilibria on each stage. The key feature of the mapping method is RD applicability graphs produced from the generic cases, which are the plots of reflux ratio (RR) vs number of theoretical stages (NTS). This study focuses on quaternary systems, as they are the most encountered reactions for the operation of RD in chemical industry. Beyond the scope of this paper, the mapping method is promising for applications to ternary systems, but further studies are required to further develop the method for those systems. The application of RD to quaternary systems investigated in this study considers different boiling point $\left(\mathrm{T}_{\mathrm{b}}\right)$ rankings and feed locations. Insights into the RD applicability related to economics and conceptual design are provided early on. This is in contrast to the conventional way, where knowledge about these aspects usually requires rigorous simulations and/or detailed calculations and at such level that understanding can be obtained only at the final stage of conceptual design studies (Seider et al., 2003; Towler and Sinnott, 2012). Firstly, the mapping method is used to obtain a preliminary economic ranking, thus providing an overview on the most beneficial RD configurations in chemical processes. Secondly, the mapping method is used to investigate the possibilities of reducing the energy requirement (i.e. operating RD with lower reflux ratios) by finding the optimal feed locations. A recent review revealed that extensive studies about the design of RD are available in literature, but there is still a lack of understanding in terms of process optimization (Segovia-Hernández et al., 2015).

Prior studies investigating the effect of volatilities on the RD performance are available in literature with different focuses and approaches. Luyben and Yu (2008) ranked quaternary reactions with various boiling point orders by using detailed economic calculations but 
1 considering only a fixed equilibrium constant. In this work, we use a range of chemical

2 equilibrium constants and rank the quaternary reactions with a simpler approach, based on number of theoretical stages and reflux ratio that provide an indication of the capital investment and energy requirement. Chen and Yu (2008) used the same approach as that in Luyben and $\mathrm{Yu}$ (2008) to study the effect of relative volatility ranking on RD configurations, but to ternary decomposition reactions only. In this study, we focus on quaternary reactions, which are more complex by the presence of more components in the systems. Our previous work (2018) focused on a single set of quaternary systems with both reactants as mid-boiling components and products as lightest and heaviest components $\left(\mathrm{T}_{\mathrm{b}, \mathrm{C}}<\mathrm{T}_{\mathrm{b}, \mathrm{A}}<\mathrm{T}_{\mathrm{b}, \mathrm{B}}<\mathrm{T}_{\mathrm{b}, \mathrm{D}}\right)$, and fixed feed locations at both end sides of the reactive section. That work provided valuable insights into RD performance considering low or high relative volatilities between productreactant $\left(\alpha_{\mathrm{CA}}\right.$ and $\left.\alpha_{\mathrm{BD}}\right)$ and both reactants $\left(\alpha_{\mathrm{AB}}\right)$. In our current study, we include all quaternary systems with different boiling point rankings and obtain the optimal feed locations considering varied feed stages.

Summing it up, this work gives useful knowledge regarding industrial RD processes, covering two aspects related to essential assessment in conceptual design studies: economic ranking of process alternatives, and optimal process configurations. Furthermore, this study provides a valuable understanding of the effect of boiling point rankings on the RD processes.

\section{Approach and methodology}

A novel mapping method - described in our previous work - has been employed to predict the applicability of RD based on the applicability graphs of generic cases and to study the effect of relative volatilities, chemical equilibrium and kinetics (represented by Damköhler number) on RD processes (Muthia et al., 2018). This method was also used to determine the optimal RD configurations that can operate at lowest costs (Muthia et al., 2018a).

The key feature of the mapping method is the RD applicability graph, illustrated in Figure 1. A boundary line in the applicability graph splits the plot into applicable and not-applicable areas. On that line, each NTS has a RD configuration with the lowest reflux ratio possible. On the boundary line and inside the applicability area at any NTS, the operation of reactive distillation is conceivable. Multiple RD configurations are available inside the applicability area which give flat-optimum solutions (Muthia et al., 2018). For the sake of clarity, the applicability graphs shown in this work have a maximum scale of 100 for both $\mathrm{x}$ - and $\mathrm{y}$-axes. Each RD applicability graph is coupled with a representation of column configurations within the applicable area. The selection of that representation can be based on various consideration, 
e.g. at a fixed NTS, at NTS $=2 \cdot \mathrm{NTS}_{\min }$, at NTS with $\mathrm{RR}=1.2 \cdot \mathrm{RR}_{\min }$, or at any other points. In this study, each representation of RD configurations is at $\mathrm{NTS}=2 \cdot \mathrm{NTS}_{\min }$ which is only based on the well-known rule of thumb in conventional distillation regarding the prediction of the optimum configuration. That representation is selected by considering the availability of multiple RD configurations with reflux ratios up to $10 \%$ larger than the lowest RR. This consideration is logically accepted as that marginal reflux ratios difference is commonly negligible in the RD application. Considering the flat-optimum solutions in the applicability graphs, various trends of RD configurations can be obtained when different applicability graphs are studied and compared. The representations of RD columns are selected based on the decrease of number of reactive stages for a higher $K_{\text {eq }}$ when applicability graphs of various equilibrium constants are compared. This selection criterion is logical since a better reaction performance is achieved for a higher $\mathrm{K}_{\mathrm{eq}}$.

The schematic procedure to generate an applicability graph is given in Figure 2. It might be preferred to specify relative volatilities of components following the boiling point rankings of the quaternary systems. For instance, with the order of $\mathrm{T}_{\mathrm{b}, \mathrm{C}}<\mathrm{T}_{\mathrm{b}, \mathrm{A}}<\mathrm{T}_{\mathrm{b}, \mathrm{D}}<\mathrm{T}_{\mathrm{b}, \mathrm{B}}$, specifying $\alpha_{\mathrm{CA}}, \alpha_{\mathrm{AD}}$ and $\alpha_{\mathrm{DB}}$ might be preferred. This study only focuses on equilibrium-limited reactions as similar knowledge is expected to be the outcome for the study of their kinetically controlled reactions, as proven in our previous work (2018). Since vapor-liquid and chemical equilibria are reached on each stage of the column, specifying liquid hold-up or residence time (resulting in the Damköhler number) is not required as an input for the simulation in this work.

The quaternary reactions are classified into six groups based on the boiling point rankings, as shown in Table 1. For consistency reasons, the naming convention of the groups follows the rule defined by Luyben and Yu (2008). To deliver comparable results for different groups, several key relative volatilities have to be specified uniformly. In this study, $\alpha_{\mathrm{AB}}$ and $\alpha_{\mathrm{CD}}$ are specified at 2 and 6 , respectively (see Table 1). Only group $I_{r}$ has different specified $\alpha_{A B}$ and $\alpha_{\mathrm{CD}}$ since its boiling point order does not allow defining those relative volatilities at 2 and 6 , respectively. Both groups $\mathrm{II}_{\mathrm{p}}$ and $\mathrm{II}_{\mathrm{r}}$ are disregarded from the investigation, since from a thermodynamic point of view, it is unfeasible to obtain two heaviest / lightest products from two lightest / heaviest reactants (in stoichiometric systems).

Using the mapping method, a preliminary economic ranking of RD is obtained here by considering the number of theoretical stages and reflux ratio as two main variables, which give the first economic assessment. NTS indicates the height of column which is proportional to the capital investment and RR affects the column diameter and is directly proportional to 
1 the amount of hot utility required (energy usage), respectively (Kiss, 2013). To perform this

2 assessment comprehensively, the chemical equilibrium constants are varied at values of: 0.01 ,

$30.1,0.2,1$ and 10. These values cover the practical range of reactions in terms of the RD 4 application.

5 All simulations are performed in Aspen Plus v8.6. The RD scheme is presented in Figure 3 (a). The RD column operates at atmospheric pressure, assuming negligible pressure drop. The reactants are fed as saturated liquid, in an equimolar ratio. The lighter reactant is fed on the bottom of reactive zone and the heavier reactant is introduced to the top of reactive zone, therefore a counter current flow occurs which allows reaction to take place along the reactive stages. Sensitivity analysis is carried out by varying the position and the length of rectifying, reactive and stripping sections. The optimization tool is used to minimize reflux ratio for any converged solutions by considering product purity at top and bottom ( $\min .99 \mathrm{~mol} \%$ ) as a hard constraint. Next, the optimal feed locations are assessed for the quaternary systems as given in the study of preliminary economic ranking. Any configurations in RD applicability graphs can be selected for this investigation. The resulting representations of column configurations in the previous section are used as base cases, in terms of numbers of rectifying, reactive and stripping stages. Sensitivity analysis is carried out by varying both positions of feed stages, as shown in Figure 3 (b). The optimization tool is used to minimize the reflux ratio by considering the same constraint as in the study of preliminary economic ranking.

\section{Results and discussion}

\subsection{Preliminary economic ranking of $R D$ processes}

Simulations in Aspen Plus v8.6 were performed for groups $I_{p}, I_{r}, I I I_{p}$ and III $_{r}$ to obtain their applicability areas accounting for various equilibrium constants (from 0.01 to 10 ). There is no applicability graph available in group $\mathrm{I}_{\mathrm{r}}$ for any specified $\mathrm{K}_{\mathrm{eq}}$ which indicates that the required product purity cannot be achieved, hence a single RD column is not applicable. An advanced RD configuration (involving two columns) might be used for this group. The RD setup might be adjusted by adding side-draw product stream(s) to the column as both desired products are mid-boiling compounds (Luyben and $\mathrm{Yu}, 2008$ ). At least an additional conventional distillation is needed to obtain the products at high purity. Besides, the application of reactive dividing wall column (R-DWC) could be considered as another option. As the application of a single column is aimed in this study, group $\mathrm{I}_{\mathrm{r}}$ is disregarded from our further consideration. 
1 Figure 4 (a), (c) and (e) depict the RD applicability graphs for groups $\mathrm{I}_{\mathrm{p}}, \mathrm{III}_{\mathrm{p}}$ and $\mathrm{III}_{\mathrm{r}}$, 2 respectively. $\mathrm{In}$ group $\mathrm{III}_{\mathrm{r}}$, the applicability area of the system with $\mathrm{K}_{\mathrm{eq}}=0.01$ could not be obtained for both NTS and RR up to 100. For these groups, the applicability area becomes larger when $\mathrm{K}_{\mathrm{eq}}$ is higher due to a higher conversion which gives the possibilities of having RD configurations with lower capital investments and reduced energy requirements (i.e. lower NTS and RR), which is as expected.

The representations of RD configurations, at various equilibrium constants, is shown in Figure 4 (b), (d) and (f) for groups $\mathrm{I}_{\mathrm{p}}, \mathrm{III}_{\mathrm{p}}, \mathrm{III}_{\mathrm{r}}$, respectively. As observed earlier, the increase of $\mathrm{K}_{\mathrm{eq}}$ leads to a better reaction performance, therefore the NTS and RR decrease for each group. In comparison between different groups, at a fixed $\mathrm{K}_{\mathrm{eq}}$, the number of theoretical stages and reflux ratio increase from group $\mathrm{I}_{\mathrm{p}}, \mathrm{III}_{\mathrm{p}}$ to $\mathrm{III}_{\mathrm{r}}$, respectively. This trend indicates the cost ranking of these three groups $-\mathrm{I}_{\mathrm{p}}, \mathrm{III}_{\mathrm{p}}, \mathrm{III}_{\mathrm{r}}$ - from the lowest to the highest cost, respectively. Having obtained the RD configurations for all groups in Figure 4 (b), (d) and (f), the column schemes are shown in Figure 5.

Considering the volatility order of group $\operatorname{III}_{\mathrm{p}}\left(\mathrm{T}_{\mathrm{b}, \mathrm{C}}<\mathrm{T}_{\mathrm{b}, \mathrm{A}}<\mathrm{T}_{\mathrm{b}, \mathrm{D}}<\mathrm{T}_{\mathrm{b}, \mathrm{B}}\right)$, it is very important to fully convert component $\mathrm{B}$ before it reaches the stripping section, otherwise its presence becomes a hindrance to a high purity of product $\mathrm{D}$ at the bottom stream. Therefore, if group III $_{p}$ is compared to group $I_{p}$, a larger number of reactive stages is required. For any fixed equilibrium constant - see Figure 4 (b) and (d) - the rectifying section of group $\mathrm{III}_{\mathrm{p}}$ is smaller than that of group $I_{p}$ because of the larger relative volatilities of compounds $\left(\alpha_{C A}=4\right.$ and $\alpha_{\mathrm{CB}}=8.4$ in group $\mathrm{III}_{\mathrm{p}}, \alpha_{\mathrm{CA}}=2$ and $\alpha_{\mathrm{CB}}=4$ in group $\mathrm{I}_{\mathrm{p}}$ ) which lead to an easier separation. Besides, the stripping section of the RD column for group $\mathrm{III}_{\mathrm{p}}$ is larger than that of group $\mathrm{I}_{\mathrm{p}}$ as the separation between reactant $A$ and product $D$ is more challenging $\left(\alpha_{A D}=3\right.$ in group $I_{p}$ and $\alpha_{\mathrm{AD}}=1.5$ in group $\mathrm{III}_{\mathrm{p}}$ ).

Regarding the relative volatility sets listed in Table 1, the configurations of group III $_{\mathrm{r}}$ are expected to be mirror images of the RD columns of group III $_{\mathrm{p}}$, shown in Figure 5 (b) and (c). However, it is observed that a higher number of theoretical stages and a larger reflux ratio are required for group $\mathrm{III}_{\mathrm{r}}$ at various $\mathrm{K}_{\mathrm{eq}} \mathrm{s}$, see Figure 4 (d) and (f). In contrast to group III $_{\mathrm{p}}$, group III $_{\mathrm{r}}$ needs a larger reactive section to fully convert the reactant $\mathrm{A}$ before it reaches the rectifying section. This task is more difficult than that in group $\mathrm{III}_{\mathrm{p}}$ because the reactant $\mathrm{A}$ is the lightest, therefore it is easily vaporized and enter the upper level of the column. A higher reflux ratio is required mainly because of more difficult separation in rectifying section $\left(\alpha_{\mathrm{CB}}=1.5\right.$ in group $\mathrm{III}_{\mathrm{r}}, \alpha_{\mathrm{CA}}=4$ and $\alpha_{\mathrm{CB}}=8.4$ in group III $\left._{\mathrm{p}}\right)$. 
1 To gain more understanding about the effect of chemical equilibrium constants on the reaction and separation processes in the different groups, the liquid composition profiles are provided in Figure 6. A low and a high $\mathrm{K}_{\mathrm{eq}} \mathrm{s}(0.1$ and 10) are evaluated for each group. For all groups with $\mathrm{K}_{\mathrm{eq}}=0.1$ - see Figure 6 (a), (c) and (e) - there is always an accumulation of a reactant along the reactive zone because it helps to push the conversion of reaction to the products side. Commonly, reactant $\mathrm{A}$ is the accumulated compound because it is more easily vaporized than reactant $\mathrm{B}$ and the condensation process at the upper part of the column changes its phase back to liquid. However, in group $\mathrm{III}_{\mathrm{r}}$ having abundant reactant A will inhibit the desired RD process as it interferes with the high purity of product $\mathrm{C}$. Therefore, in this group at a low $\mathrm{K}_{\mathrm{eq}}$, $\mathrm{B}$ is the reactant that is accumulated.

If the systems with an equilibrium constant $\mathrm{K}_{\mathrm{eq}}=10$ are compared to those with $\mathrm{K}_{\mathrm{eq}}=0.1$, the accumulation in the reactive zone of any reactant is then replaced by the product(s) due to a better reaction performance. In group $I_{p}$ - see Figure 6 (b) - the accumulation of products $C$ and $\mathrm{D}$ in the reactive zone can be observed, with a higher mol fraction of D present. Less accumulated $\mathrm{C}$ is detected, because overall the separation of product $\mathrm{C}$ from any reactants is easier $\left(\alpha_{C A}=2, \alpha_{C B}=4, \alpha_{A D}=3, \alpha_{B D}=1.5\right)$. In group $I_{\mathrm{p}}$ - see Figure $6(d)-$ component $D$ is the accumulated product because its separation from reactant $\mathrm{A}$ is more challenging than that of product $C$ considering their relative volatilities $\left(\alpha_{A D}=1.5, \alpha_{C A}=4\right)$. The opposite difficulty occurs in group $\mathrm{III}_{\mathrm{r}}$, see Figure 6 (f), in which the separation between reactant B and product $\mathrm{C}$ is more challenging than the separation between reactant $\mathrm{B}$ and product $\mathrm{D}\left(\alpha_{\mathrm{CB}}=1.5\right.$, $\left.\alpha_{\mathrm{BD}}=4\right)$, therefore $\mathrm{C}$ is the accumulated product in the column.

\subsection{Optimal feed locations for RD units}

The optimization of feed locations has been carried out by taking the RD configurations as given in Figure 4 (b), (d) and (f) with $\mathrm{K}_{\mathrm{eq}}=1$ as the base cases. For all combinations of feed locations, the numbers of rectifying, reactive and stripping stages remain the same as those in the base cases, which limit the varied design parameters and give clarity to the presented results. Figure 7 (a), (b) and (c) show reflux ratios as a contour plot for varied feed locations of both reactants $\mathrm{A}$ and $\mathrm{B}$ for groups $\mathrm{I}_{\mathrm{p}}, \mathrm{III}_{\mathrm{p}}$ and $\mathrm{III}_{\mathrm{r}}$, respectively, at $\mathrm{K}_{\mathrm{eq}}=1$. Cross and square marks in each plot indicate the base case and a RD configuration with the most optimal feed locations (i.e. with the lowest reflux ratio reducing energy requirements), respectively. Moving from the crosses to the squares, the reflux ratios of the base cases decrease from 2.1 to 1.7 for group $\mathrm{I}_{\mathrm{p}}$ (19\% reduction), from 4.6 to 2.9 for group $\mathrm{III}_{\mathrm{p}}(37 \%$ reduction), and from 8.6 to 6.6 for group III $_{\mathrm{r}}$ (23\% reduction), by adjusting the feed locations. 
1 To clearly distinguish the RR changes, each plot in Figure 7 is partitioned based on certain 2 RD ranges and marked with distributed colors. The optimal region (the darkest zone) in each 3 plot is achieved by RD configurations with reflux ratios up to 3\% higher than the lowest RR.

4 For all groups, it is always beneficial to have a shorter distance between the two feed stages, therefore an immediate contact between two reactants occur before separation takes place. Besides, it is essential to set the feed stage of reactant B (as the higher boiling reactant) above that of reactant $\mathrm{A}$ in order to enhance the direct contact of both reactants in liquid phase, therefore enhancing the reaction performance. Placing the feed inlets on a reverse order causes a significant increase in reflux ratios. For instance, in group $I_{p}$, the feed stages of reactants $A$ and $B$ at 24 and 11 require $R R=2.1$, while the reverse order gives $R R=8.1$. In group $\mathrm{III}_{\mathrm{p}}, \mathrm{RR}=3.8$ is needed when the feed inlets of reactants $\mathrm{A}$ and $\mathrm{B}$ are at stages 12 and 4 , while the reverse order requires $R R=10.9$. In group $\mathrm{III}_{r}, \mathrm{RR}=6.9$ is needed when the feed inlets of reactants A and B are at stages 56 and 44, while the reverse order requires $R R=44.3$. Moving from the crosses to the squares in Figure 7, the optimization pattern for different groups are identified. In group $\mathrm{I}_{\mathrm{p}}$, the RD process is optimized by positioning the two feed stages close to the centre part of the reactive zone. In group $\mathrm{III}_{\mathrm{p}}$, bringing the inlet of reactant A up within the reactive zone reduces the energy requirements (lower RR). On the contrary, lowering the feed stage of reactant $\mathrm{B}$ closer to the bottom section of reactive stages decreases the energy requirements (lower RR) in group III $_{\mathrm{r}}$. For a better insight, the representations of RD configurations with lowest reflux ratios inside the darkest zone in Figure 8 (b), (d) and (f) are coupled with the corresponding column configurations of the base cases, as shown in Figure 8 (a), (c) and (e).

Further investigation is performed by observing the liquid composition profiles of different groups, as given in Figure 9. In comparison to the base case of group $I_{p}$, see Figure 9 (a) and (b), the immediate contact of reactants for the optimized feed stages has reduced their accumulation along the RD column. As consequence, there are less unreacted compounds found in the rectifying and stripping sections which results in less difficulty in the separation. In group III $_{p}$ - see Figure 9 (c) and (d) - the improved reaction condition in the reactive zone with modified feed locations significantly helps to eliminate reactant B (i.e. the heaviest compound in this group). The average concentration of $\mathrm{A}$ in the reaction zone has increased with at the same time a lower concentration of $\mathrm{A}$ at the bottom part of the reactive zone compare Figure 9 (c) and (d) - which reduces the concentration of B even further and improves the separation performance (lower reflux ratio) for A/D. In the base case of group 
1 performance and to prevent reactant A from reaching the upper part of column. In the 2 improved RD process, the distribution of accumulated reactant $\mathrm{B}$ in the reactive zone has been 3 optimized which is implied by the shift of the peak of its mol fraction and the increase in average concentration of B in the reactive zone, as shown in Figure 9 (f). This shift reduces the amount of $\mathrm{B}$ going up the rectifying section, therefore the separation of product $\mathrm{C}$ is easier.

Although a closer distance between the two feed stages is preferred in each group, introducing reactants $\mathrm{A}$ and $\mathrm{B}$ at the same stage potentially increases the energy requirements (higher RR) because reactant $\mathrm{A}$ is partially vaporized at the same time when reactant $\mathrm{B}$ moves down to the lower level of the column prior to reaching the reaction conditions. This observation indicates the competition between reaction and separation on a reactive stage.

For the validation of our findings, we refer to a RD configuration with the optimal feed locations for the methyl acetate production, as provided by Tang et al. (2005) by performing rigorous simulations and detailed economic calculations. The synthesis of methyl acetate via esterification is given in Eq. (1). Based on its boiling points ranking, this reaction is classified into group $\mathrm{III}_{\mathrm{p}}\left(\mathrm{T}_{\mathrm{b}, \mathrm{C}}<\mathrm{T}_{\mathrm{b}, \mathrm{A}}<\mathrm{T}_{\mathrm{b}, \mathrm{D}}<\mathrm{T}_{\mathrm{b}, \mathrm{B}}\right)$.

$$
\text { Methanol }(\mathbf{A})+\text { Acetic acid }(\mathbf{B}) \rightleftharpoons \text { Methyl acetate }(\mathbf{C})+\text { Water }(\mathbf{D})
$$

$\mathrm{T}_{\mathrm{b}}$

$64.7^{\circ} \mathrm{C}$

$118.01{ }^{\circ} \mathrm{C}$

$56.94{ }^{\circ} \mathrm{C}$

$100{ }^{\circ} \mathrm{C}$

$\Delta \mathrm{H}_{\mathrm{r}}=-15.85 \mathrm{~kJ} / \mathrm{mol}$

The optimal RD configuration reported by Tang et al. (2005) consists of 1 rectifying, 34 reactive and 4 stripping stages including reboiler. The feed locations of acetic acid (the heavier reactant) and methanol (the lighter reactant) are at stage 3 and 26, respectively, counted from the top down, which matches the predicted region of the optimal feed locations of group $\mathrm{III}_{\mathrm{p}}$ as suggested by this work, see Figure 7 (b) and Figure 8 (c), (d). This example confirms the promising application of the mapping method. Besides the methyl acetate production, Tang et al. (2005) assessed the optimal RD designs for other acetic acid esterification reactions producing ethyl acetate, isopropyl acetate, n-butyl acetate and amyl acetate. Due to the higher level of complexity in those systems (i.e. the presence of ternary and heterogeneous azeotropes), it was reported that the operation of a single RD column is not feasible and therefore RD columns with decanter and/or additional stripper are required. For these different RD setups, the approach provided by this work is not applicable. 


\section{4. Conclusions}

2 This work successfully demonstrates the use of the mapping method for obtaining insightful knowledge of RD processes by using generic cases. Two essential aspects in conceptual design (i.e. economic ranking of configurations and process optimization) can be investigated at an early stage, instead of being assessed at the final stage of conventional studies.

The boiling point rankings of components have significant effects on RD configurations. In the case of comparable chemical equilibrium constants and relative volatilities, the preliminary cost ranking of quaternary systems for the application of a single RD column is: group $\mathrm{I}_{\mathrm{p}}<\mathrm{III}_{\mathrm{p}}<\mathrm{III}_{\mathrm{r}}$ (from the lowest to the highest cost). A single RD column setup cannot be applied to group $\mathrm{I}_{\mathrm{r}}$ considering the challenging separation of both mid-boiling products from the lightest and the heaviest boiling reactants. The presented approach can be used to assess other equilibrium constants and relative volatility sets, significantly improving the understanding of RD processes for different cases.

The mapping method is also useful to determine the regions where the optimal feed locations are obtained. In group $I_{p}$, it is more beneficial to position both feed inlets closer to the centre of the reactive zone. In group $\mathrm{III}_{\mathrm{p}}$, lower energy usage (reflux ratios) can be obtained by putting the inlet of reactant $\mathrm{A}$ within the reactive zone, while the inlet of reactant B is kept at the top of the reactive zone. In contrast, for group $\mathrm{III}_{\mathrm{r}}$, it is more beneficial to feed reactant $\mathrm{B}$ within the reactive zone, while keeping the inlet of reactant $\mathrm{A}$ at the bottom of the reactive zone. For all groups, a shorter distance between two feed inlets gives benefits, with the inlet of the heavier reactant always above the inlet of the lighter reactant. However, feeding both reactants at the same stage is detrimental for the energy usage since the competition between reaction and separation phenomena hinders the RD performance.

\section{Acknowledgment}

The contribution of full financial fund from the LPDP (Indonesia Endowment Fund for Education) for R. Muthia is greatly acknowledged. A. A. Kiss gratefully acknowledges the Royal Society Wolfson Research Merit Award. The author also thanks all the participants of the Distillation \& Absorption conference 2018 (Florence, Italy) for the useful discussions, and the reviewers for their insightful comments and suggestions. 


\section{$1 \quad$ Nomenclature}

$2 K_{e q} \quad$ chemical equilibrium constant [-]

$3 N_{\text {min }} \quad$ minimum number of theoretical stages [-]

4 NTS number of theoretical stages [-]

$5 \quad R R \quad$ reflux ratio $[\mathrm{mol} / \mathrm{mol}]$

$6 \quad R R_{\min } \quad$ minimum reflux ratio $[\mathrm{mol} / \mathrm{mol}]$

$7 \quad T_{b} \quad$ boiling point temperature $\left[{ }^{\circ} \mathrm{C}\right]$

$8 \quad \alpha_{i j} \quad$ relative volatility between component $\mathrm{i}$ and $\mathrm{j}[-]$

$9 \Delta \mathrm{H}_{\mathrm{r}} \quad$ heat of reaction $[\mathrm{kJ} / \mathrm{mol}]$

\section{References}

Agreda, V. H., Partin, L. R., Heise, W. H., 1990. High-Purity Methyl Acetate via Reactive Distillation. Chemical Engineering Progress. 40-46. Almeida-Rivera, C. P., Swinkels, P. L. J., Grievink, J., 2004. Designing reactive distillation processes: present and future. Comput. Chem. Eng. 28, 1997-2020.

Barbosa, D., Doherty, M. F., 1988a. Design and minimum reflux-calculations for single-feed multicomponent reactive distillation columns. Chem. Eng. Sci. 43, 1523-1537.

Barbosa, D., Doherty, M. F., 1988b. Design and minimum-reflux calculations for double-feed multicomponent reactive distillation columns. Chem. Eng. Sci. 43, 2377-2389.

Baur, R., Higler, A. P., Taylor, R., Krishna, R., 2000. Comparison of equilibrium stage and nonequilibrium stage models for reactive distillation. Chem. Eng. J. 76, 33-47.

Buzad, G., Doherty, M. F., 1994. Design of three-component kinetically controlled reactive distillation columns using fixed-points methods. Chem. Eng. Sci. 49, 1947-1963.

Chen, B.-C., Yu, B.-Y., Lin, Y.-L., Huang, H.-P., Chien, I. L., 2014. Reactive-Distillation Process for Direct Hydration of Cyclohexene to Produce Cyclohexanol. Ind. Eng. Chem. Res. 53, 7079-7086.

Chen, C.-S., Yu, C.-C., 2008. Effects of Relative Volatility Ranking on Design and Control of Reactive Distillation Systems with Ternary Decomposition Reactions. Industrial \& Engineering Chemistry Research. 47, 4830-4844.

Chen, F., Huss, R. S., Malone, M. F., Doherty, M. F., 2000. Simulation of kinetic effects in reactive distillation. Comput. Chem. Eng. 24, 2457-2472. acetol via catalytic reactive distillation. AIChE J. 52, 3543-3548. 
1 Ciric, A. R., Gu, D., 1994. Synthesis of nonequilibrium reactive distillation processes by 2 MINLP optimization. AIChE J. 40, 1479-1487.

3 González, D. R., Bastidas, P., Rodríguez, G., Gil, I., 2017. Design alternatives and control 4 performance in the pilot scale production of isoamyl acetate via reactive distillation. Chem. 5 Eng. Res. Des. 123, 347-359.

6 Groemping, M., Dragomir, R.-M., Jobson, M., 2004. Conceptual design of reactive 7 distillation columns using stage composition lines. Chem. Eng. Process. Process Intensif. 43, 369-382.

Harmsen, G. J., 2007. Reactive distillation: The front-runner of industrial process intensification: A full review of commercial applications, research, scale-up, design and operation. Chem. Eng. Process. Process Intensif. 46, 774-780. Jantharasuk, A., Gani, R., Górak, A., Assabumrungrat, S., 2011. Methodology for design and analysis of reactive distillation involving multielement systems. Chem. Eng. Res. Des. 89, 1295-1307.

Kaur, J., Sangal, V. K., 2017. Reducing energy requirements for ETBE synthesis using reactive dividing wall distillation column. Energy. 126, 671-676.

Kiss, A. A., 2013. Novel applications of dividing-wall column technology to biofuel production processes. J. Chem. Technol. Biotechnol. 88, 1387-1404.

Kiss, A. A., 2018. Novel Catalytic Reactive Distillation Processes for a Sustainable Chemical Industry. Top. Catal.

Lee, J. W., Hauan, S., Westerberg, A. W., 2000. Graphical Methods for Reactive Distribution in a Reactive Distillation Column. AIChE J. 46, 1218-1233.

Li, H., Meng, Y., Li, X., Gao, X., 2016. A fixed point methodology for the design of reactive distillation columns. Chem. Eng. Res. Des. 111, 479-491.

Luyben, W. L., Yu, C.-C., 2008. Reactive Distillation Design and Control. John Wiley \& Sons, Inc., USA.

Malone, M. F., Doherty, M. F., 2000. Reactive Distillation. Ind. Eng. Chem. Res. 39, 39533957.

29 Muthia, R., Reijneveld, A. G. T., van der Ham, A. G. J., ten Kate, A. J. B., Bargeman, G., Kersten, S. R. A., Kiss, A. A., 2018. Novel method for mapping the applicability of reactive distillation. Chem. Eng. Process. Process Intensif. 128, 263-275. 
1 Muthia, R., van der Ham, A. G. J., Kiss, A. A., 2018b. Preliminary economic ranking of 2 reactive distillation processes using a navigation method. Comput. Aided Chem. Eng. 43, $3 \quad 827-832$.

4 Segovia-Hernández, J. G., Hernández, S., Bonilla Petriciolet, A., 2015. Reactive distillation: 5 A review of optimal design using deterministic and stochastic techniques. Chem. Eng. 6 Process. Process Intensif. 97, 134-143.

7 Seider, W. D., Seader, J. D., Lewin, D. R., 2003. Product and Process Design Principles: 8 Synthesis, Analysis, and Evaluation. John Wiley and Sons, Inc., USA.

9 Shah, M., Kiss, A. A., Zondervan, E., de Haan, A. B., 2012. A systematic framework for the feasibility and technical evaluation of reactive distillation processes. Chem. Eng. Process.

11 Process Intensif. 60, 55-64.

Sharma, M. M., Mahajani, S. M., 2002. Industrial Applications of Reactive Distillation, in: Sundmacher, K., Kienle, A. (Eds.), Reactive Distillation: Status and Future Directions. Wiley-VCH Verlag GmbH \& Co. KGaA, Germany. Stankiewicz, A., 2003. Reactive separations for process intensification: an industrial perspective. Chem. Eng. Process. Process Intensif. 42, 137-144. Subawalla, H., Fair, J. R., 1999. Design Guidelines for Solid-Catalyzed Reactive Distillation Systems. Ind. Eng. Chem. Res. 38, 3696-3709.

Tang, Y.-T., Chen, Y.-W., Huang, H.-P., Yu, C.-C., Hung, S.-B., Lee, M.-J., 2005. Design of reactive distillations for acetic acid esterification. AIChE Journal. 51, 1683-1699.

21 Taylor, R., Krishna, R., 2000. Modelling reactive distillation. Chem. Eng. Sci. 55, 5183-5229. 22 Thery, R., Meyer, X. M., Joulia, X., Meyer, M., 2005. Preliminary Design of Reactive 23 Distillation Columns. Chem. Eng. Res. Des. 83, 379-400.

24 Towler, G., Sinnott, R., 2012. Chemical Engineering Design: Principles, Practice and 25 Economics of Plant and Process Design. Butterworth-Heinemann, USA.

26 Wang, S.-J., Cheng, S.-H., Chiu, P.-H., Huang, K., 2014. Design and Control of a Thermally 27 Coupled Reactive Distillation Process Synthesizing Diethyl Carbonate. Ind. Eng. Chem. Res. $2853,5982-5995$. 


\section{Table}

2 Table 1. Groups of quaternary systems $(A+B \rightleftarrows C+D)$ based on boiling point $\left(T_{b}\right)$ orders.

\begin{tabular}{|c|c|c|c|c|c|c|}
\hline \multirow[t]{2}{*}{ Group } & \multirow{2}{*}{$\begin{array}{c}\text { Boiling point } \\
\text { ranking }\end{array}$} & \multicolumn{2}{|c|}{$\begin{array}{c}\text { Specified } \\
\text { variables }\end{array}$} & \multicolumn{2}{|c|}{ Set variables } & \multirow[t]{2}{*}{$\alpha$ set following $\mathbf{T}_{b}$ order } \\
\hline & & $\alpha_{\mathrm{AB}}$ & $\alpha_{\mathrm{CD}}$ & $\alpha_{\mathrm{CA}}$ & $\alpha_{\mathrm{BD}}$ & \\
\hline $\mathbf{I}_{\mathbf{p}}$ & $\mathrm{C}<\mathrm{A}<\mathrm{B}<\mathrm{D}$ & 2 & 6 & 2 & 1.5 & $\alpha_{\mathrm{CA}}=2, \alpha_{\mathrm{AB}}=2, \alpha_{\mathrm{BD}}=1.5$ \\
\hline $\mathbf{I}_{\mathbf{r}}$ & $\mathrm{A}<\mathrm{C}<\mathrm{D}<\mathrm{B}$ & 6 & 2 & 0.6 & 0.6 & $\alpha_{\mathrm{AC}}=1.7, \alpha_{\mathrm{CD}}=2, \alpha_{\mathrm{DB}}=1.7$ \\
\hline $\mathbf{I I}_{\mathrm{p}}$ & $\mathrm{C}<\mathrm{D}<\mathrm{A}<\mathrm{B}$ & \multirow{2}{*}{\multicolumn{5}{|c|}{ disregarded from consideration, for thermodynamic reasons }} \\
\hline $\mathbf{I I}_{\mathbf{r}}$ & $\mathrm{A}<\mathrm{B}<\mathrm{C}<\mathrm{D}$ & & & & & \\
\hline III $_{p}$ & $\mathrm{C}<\mathrm{A}<\mathrm{D}<\mathrm{B}$ & 2.1 & 6 & 4 & 0.7 & $\alpha_{\mathrm{CA}}=4, \alpha_{\mathrm{AD}}=1.5, \alpha_{\mathrm{DB}}=1.4$ \\
\hline III $_{\mathbf{r}}$ & $\mathrm{A}<\mathrm{C}<\mathrm{B}<\mathrm{D}$ & 2.1 & 6 & 0.7 & 4 & $\alpha_{\mathrm{AC}}=1.4, \alpha_{\mathrm{CB}}=1.5, \alpha_{\mathrm{BD}}=4$ \\
\hline
\end{tabular}


$1 \quad$ Figure captions (auto-updated)

2 Figure 1. An illustrative applicability graph for reactive distillation (Muthia et al., 2018).

3 Figure 2. Schematic procedure to generate RD applicability graph (Muthia et al., 2018).

4 Figure 3. RD columns with (a) fixed feed inlets on the top and the bottom parts of reactive zone and (b) varied feed inlets along the RD column.

6 Figure 4. RD applicability graphs and their configurations at $\mathrm{NTS}=2 \cdot \mathrm{NTS}_{\min }$ for: (a) group $\mathrm{I}_{\mathrm{p}}$, 7 (b) group $\mathrm{III}_{\mathrm{p}}$, (c) group $\mathrm{III}_{\mathrm{r}}$. All the relative volatilities are according to Table 1 (Muthia et al., 8 2018b).

9 Figure 5. RD column schemes for (a) group $\mathrm{I}_{\mathrm{p}}$, (b) group $\mathrm{III}_{\mathrm{p}}$, (c) group $\mathrm{III}_{\mathrm{r}}$ (Muthia et al., 2018b).

Figure 6. The composition profiles of $\mathrm{RD}$ configurations at $\mathrm{NTS}=2 \cdot \mathrm{NTS}_{\min }$ for group $\mathrm{I}_{\mathrm{p}}$ considering (a) $\mathrm{K}_{\mathrm{eq}}=0.1$ and (b) $\mathrm{K}_{\mathrm{eq}}=10$, group $\mathrm{III}_{\mathrm{p}}$ considering (c) $\mathrm{K}_{\mathrm{eq}}=0.1$ and (d) $\mathrm{K}_{\mathrm{eq}}=10$, group III $_{\mathrm{r}}$ considering (e) $\mathrm{K}_{\mathrm{eq}}=0.1$ and (f) $\mathrm{K}_{\mathrm{eq}}=10$. All relative volatilities are according to Table 1.

Figure 7. Varied feed locations of both reactants A and B and their corresponding RRs at $\mathrm{K}_{\mathrm{eq}}=1$ for (a) group $\mathrm{I}_{\mathrm{p}}$, (b) group $\mathrm{III}_{\mathrm{p}}$ and (c) group $\mathrm{III}_{\mathrm{r}}$. Cross and square indicate the base cases and the RD configurations with the most optimal feed locations, respectively. Figure 8. RD column schemes in case of fixed feed inlets at the top and the bottom parts of reactive zone for (a) group $\mathrm{I}_{\mathrm{p}}$, (c) group $\mathrm{III}_{\mathrm{p}}$, (e) group $\mathrm{III}_{\mathrm{r}}$ and in case of varied feed inlets to obtain the lowest RR possible for (b) group $\mathrm{I}_{\mathrm{p}}$, (d) group $\mathrm{III}_{\mathrm{p}}$, (f) group $\mathrm{III}_{\mathrm{r}}$. The presented numbers next to the column show the RD stages. All RD column configurations are at $\mathrm{NTS}=2 \cdot \mathrm{NTS}_{\min }$ in the applicability graph considering $\mathrm{K}_{\mathrm{eq}}=1$.

Figure 9. The composition profiles of RD column configurations in case of fixed feed inlets at the top and the bottom parts of reactive zone for (a) group $\mathrm{I}_{\mathrm{p}}$, (c) group $\mathrm{III}_{\mathrm{p}}$, (e) group $\mathrm{III}_{\mathrm{r}}$ and in case of varied feed inlets to obtain the lowest RR possible for (b) group $\mathrm{I}_{\mathrm{p}}$, (d) group $\mathrm{III}_{\mathrm{p}}$, (f) group III $_{\mathrm{r}}$. The vertical solid lines always show the top and the bottom parts of reactive zone, and also the feed inlets in (a), (c), (e). The vertical dash lines in (b), (d), (f) present the feed inlets. All RD column configurations are at $\mathrm{NTS}=2 \cdot \mathrm{NTS}_{\min }$ in the applicability graph considering $\mathrm{K}_{\mathrm{eq}}=1$, and relative volatilities according to Table 1 . 

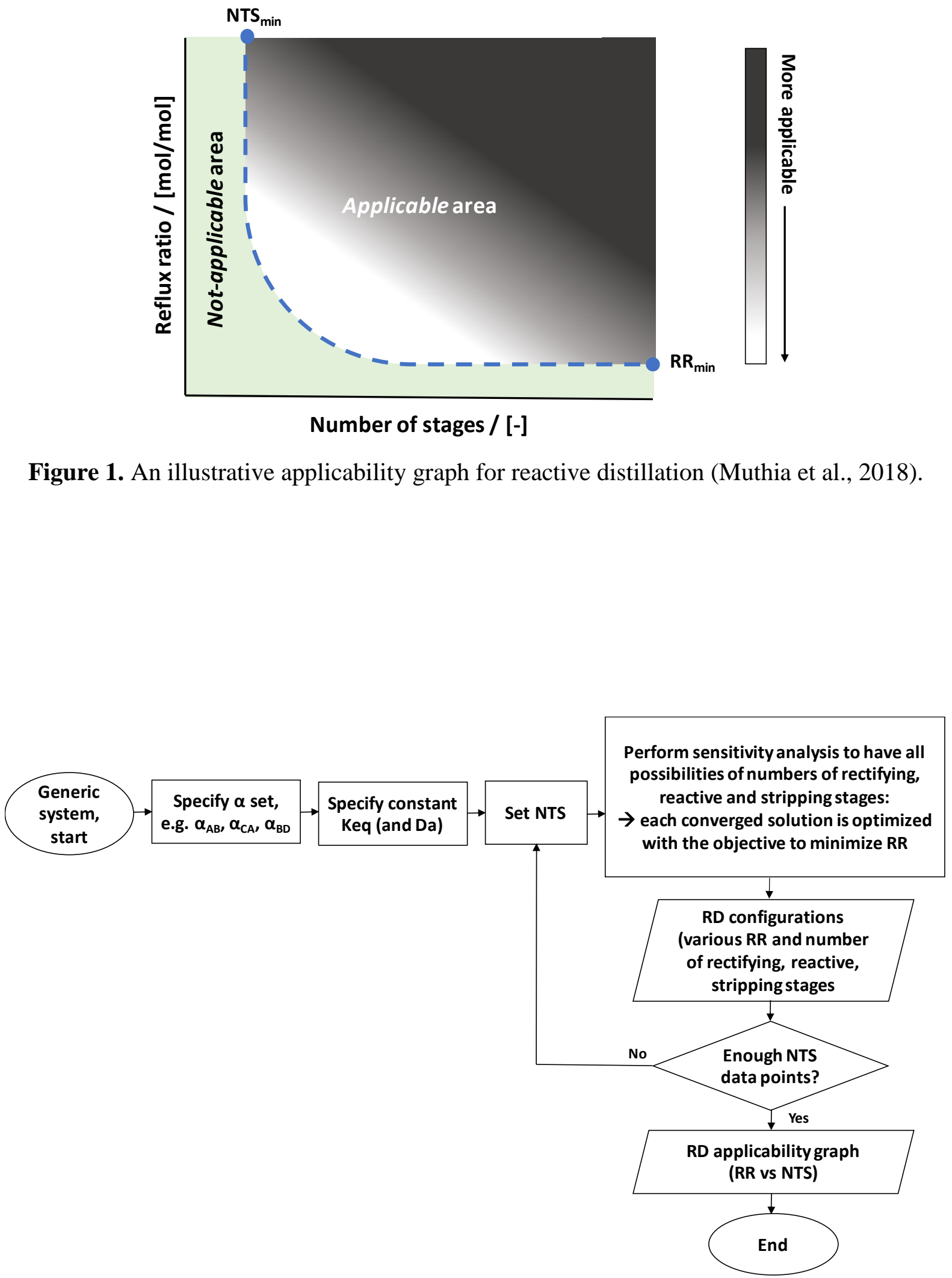

10 Figure 2. Schematic procedure to generate RD applicability graph (Muthia et al., 2018). 
1

2

3

4

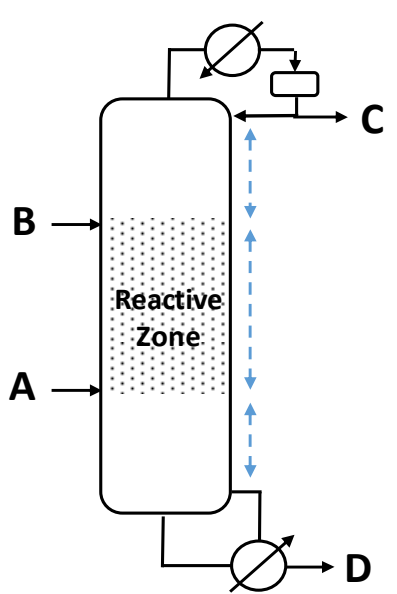

(a)

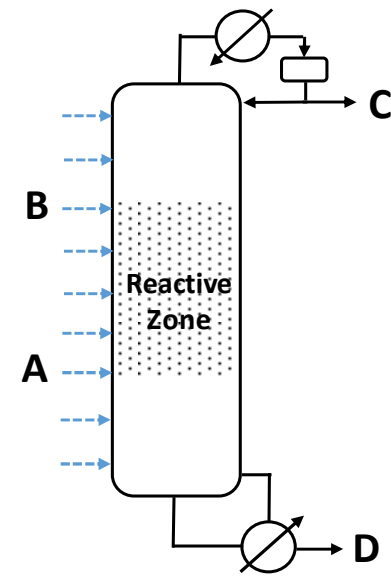

(b)

Figure 3. RD columns with (a) fixed feed inlets on the top and the bottom parts of reactive zone and (b) varied feed inlets along the RD column. 


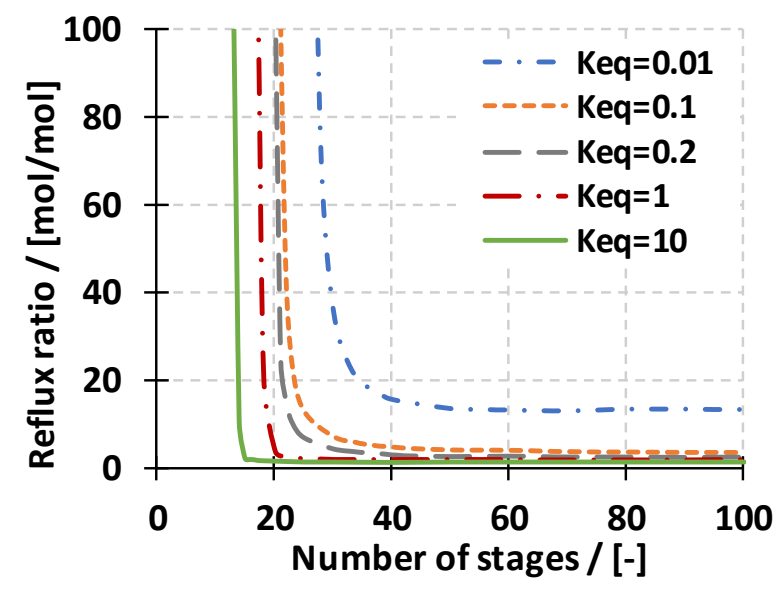

(a)

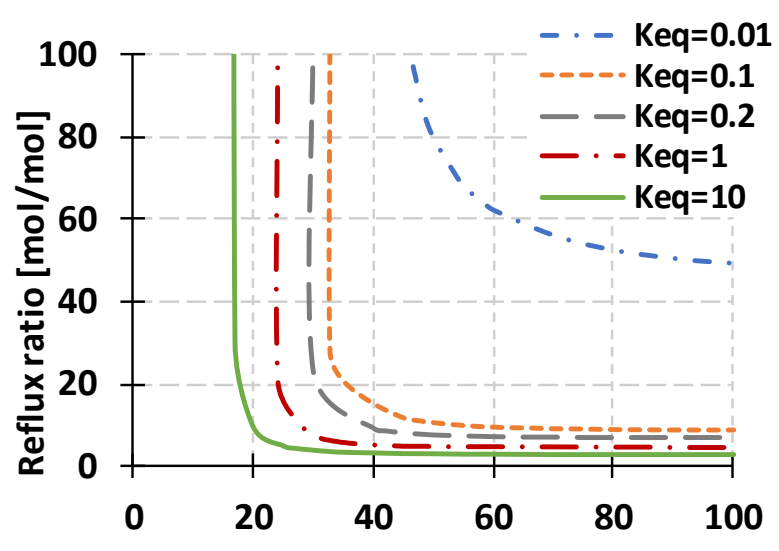

Number of stages / [-]

(c)

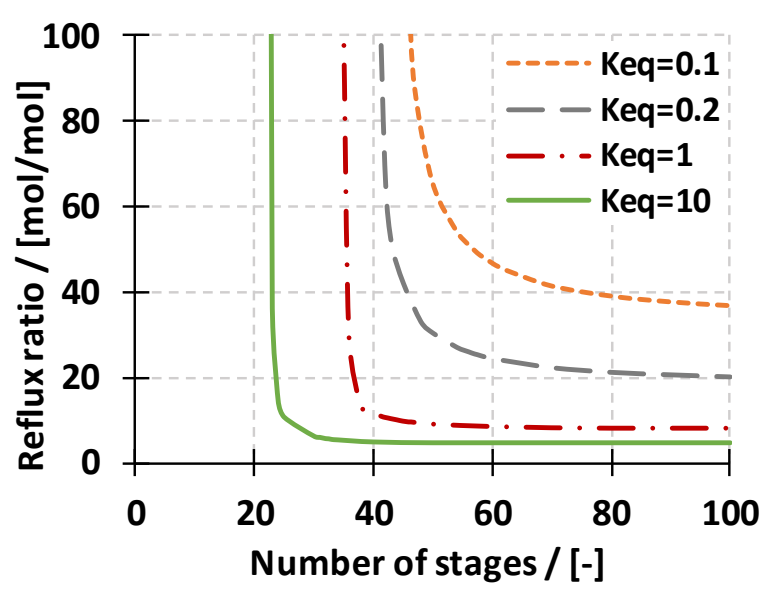

(e)

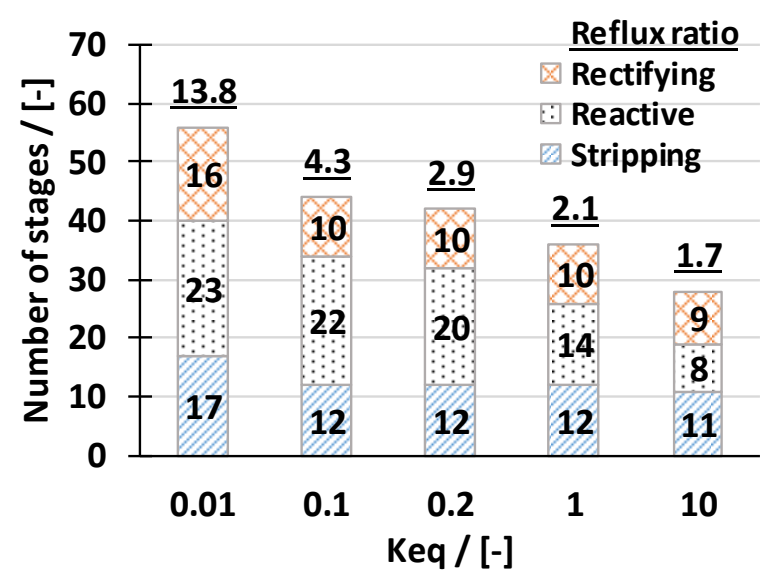

(b)

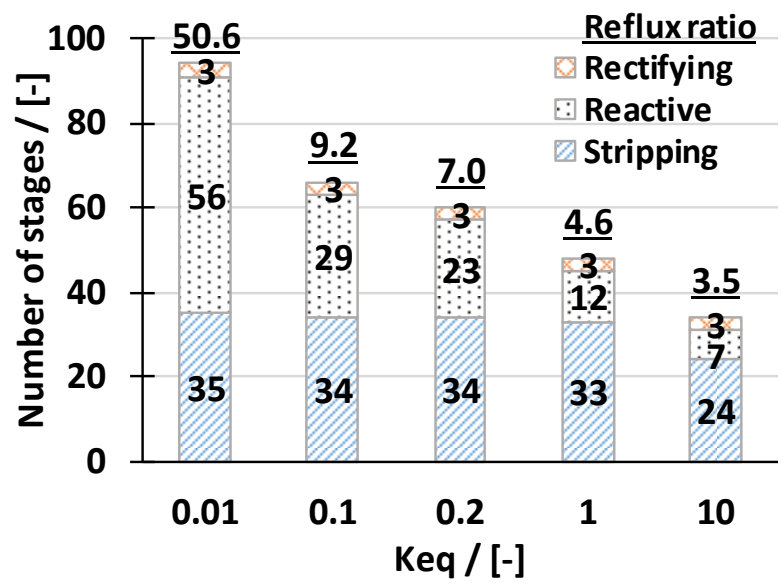

(d)

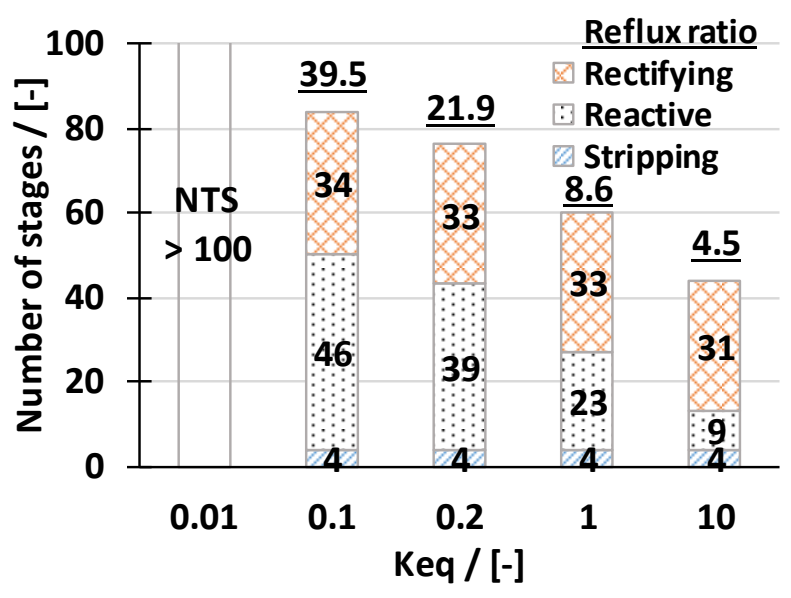

(f)

Figure 4. RD applicability graphs and their configurations at NTS $=2 \cdot \mathrm{NTS}_{\min }$ for: (a) group $\mathrm{I}_{\mathrm{p}}$, (b) group $\mathrm{III}_{\mathrm{p}}$, (c) group $\mathrm{III}_{\mathrm{r}}$. All the relative volatilities are according to Table 1 (Muthia et al., 2018b). 


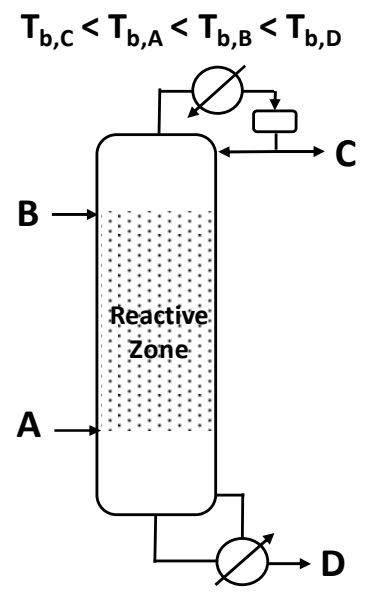

(a)

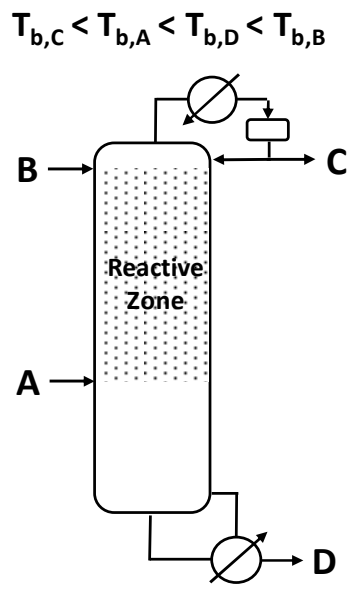

(b)

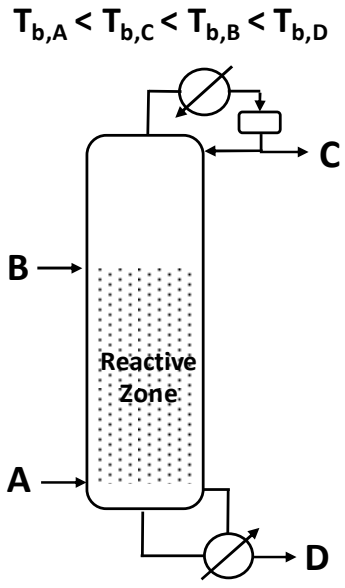

(c)

Figure 5. RD column schemes for (a) group $\mathrm{I}_{\mathrm{p}}$, (b) group $\mathrm{III}_{\mathrm{p}}$, (c) group $\mathrm{III}_{\mathrm{r}}$ (Muthia et al., 6 2018b). 


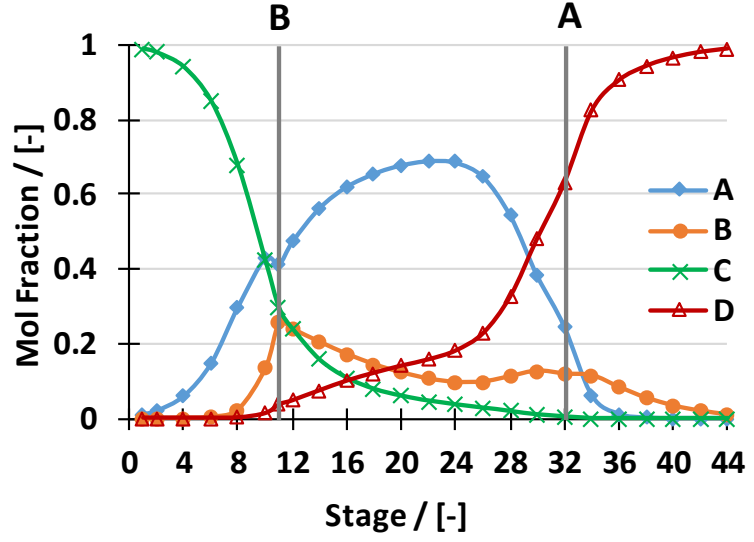

(a)

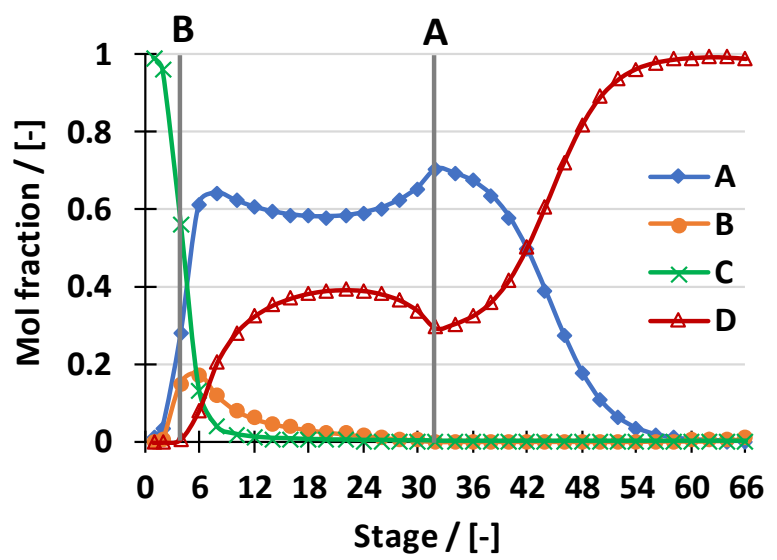

(c)

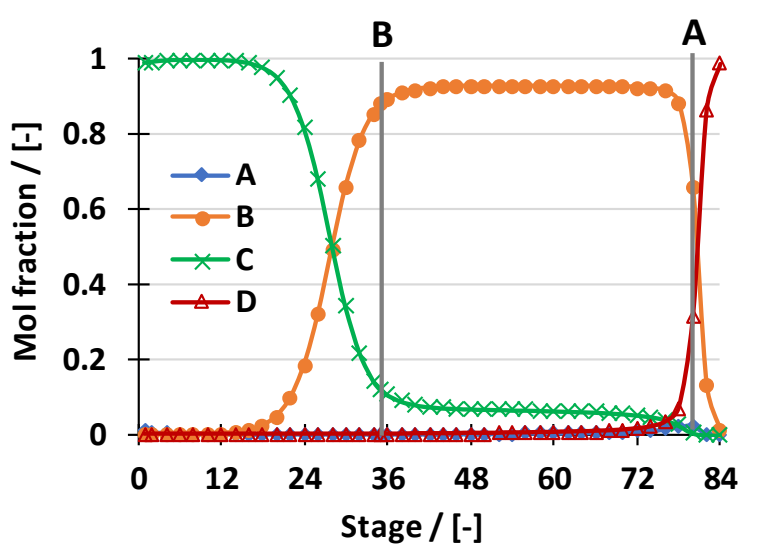

(e)

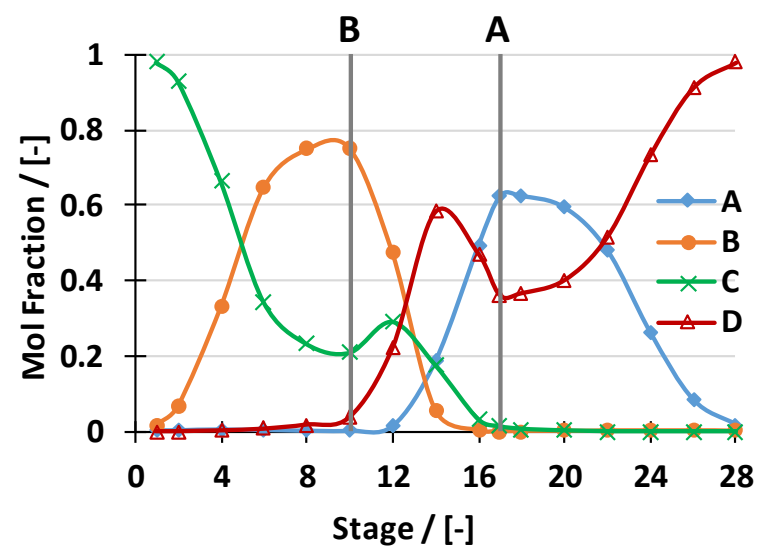

(b)

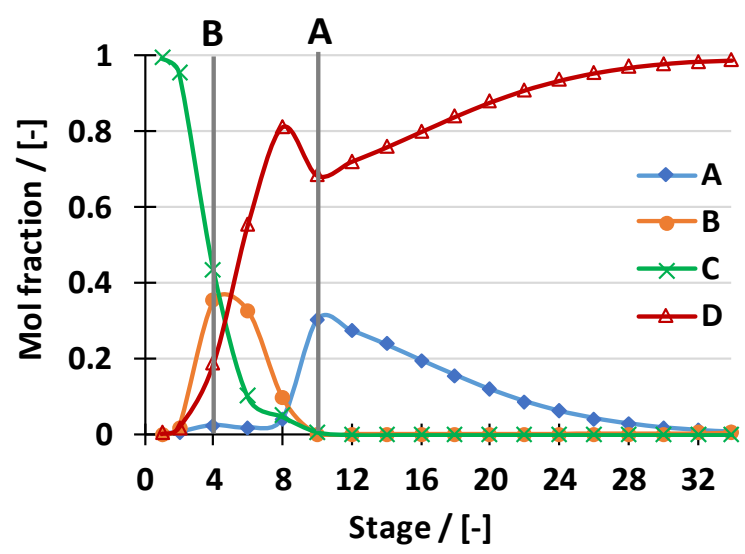

(d)

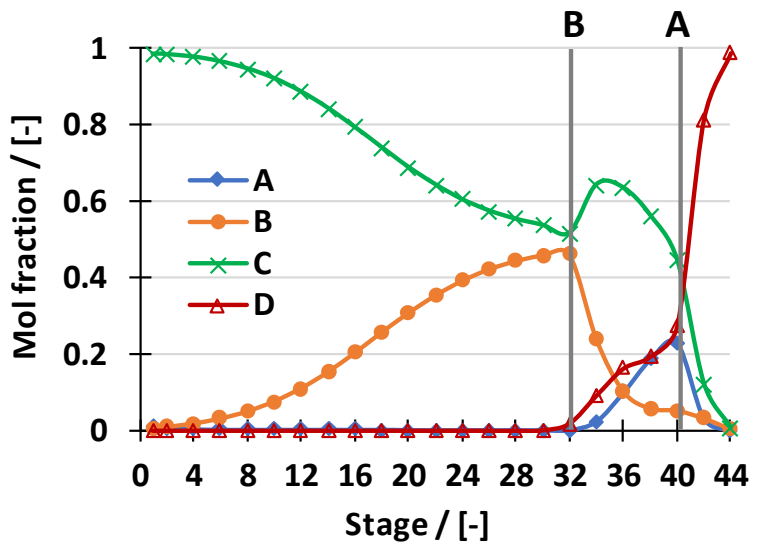

(f)

Figure 6. The composition profiles of RD configurations at $\mathrm{NTS}=2 \cdot \mathrm{NTS}_{\min }$ for group $\mathrm{I}_{\mathrm{p}}$ considering (a) $K_{e q}=0.1$ and (b) $K_{e q}=10$, group III $_{p}$ considering (c) $K_{e q}=0.1$ and (d) $K_{e q}=10$, group $\mathrm{III}_{\mathrm{r}}$ considering (e) $\mathrm{K}_{\mathrm{eq}}=0.1$ and (f) $\mathrm{K}_{\mathrm{eq}}=10$. All relative volatilities are according to

Table 1. 


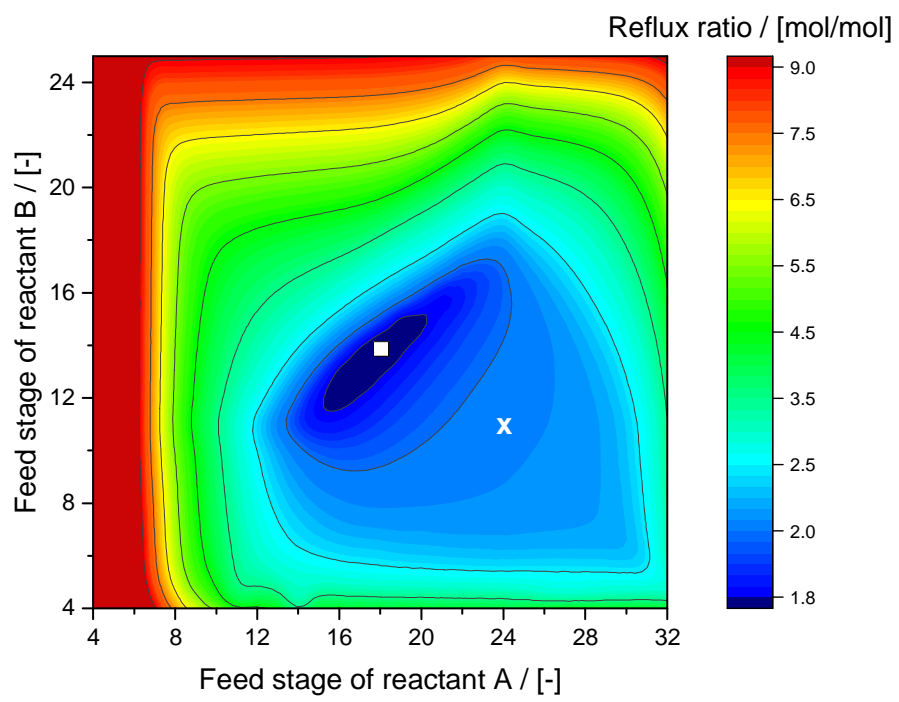

(a)

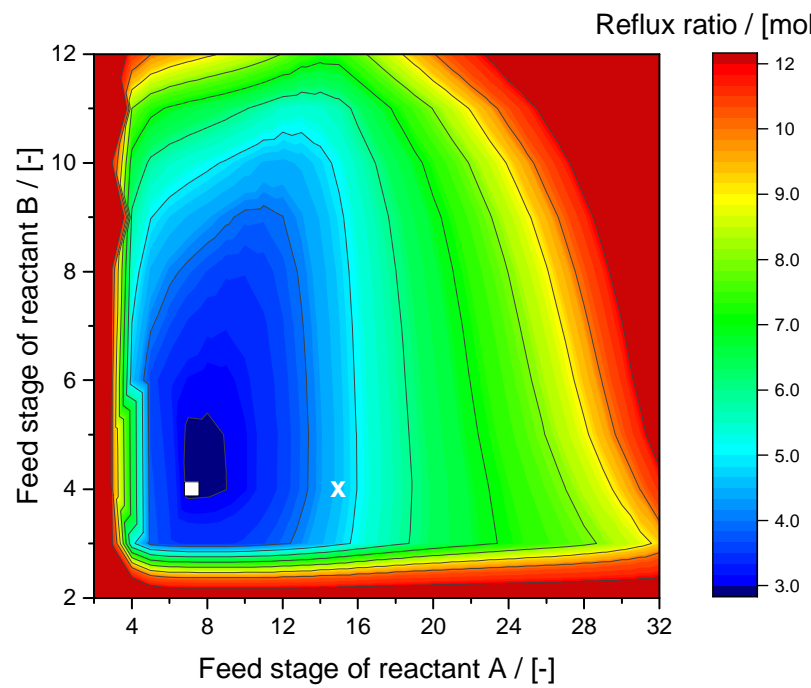

(b)

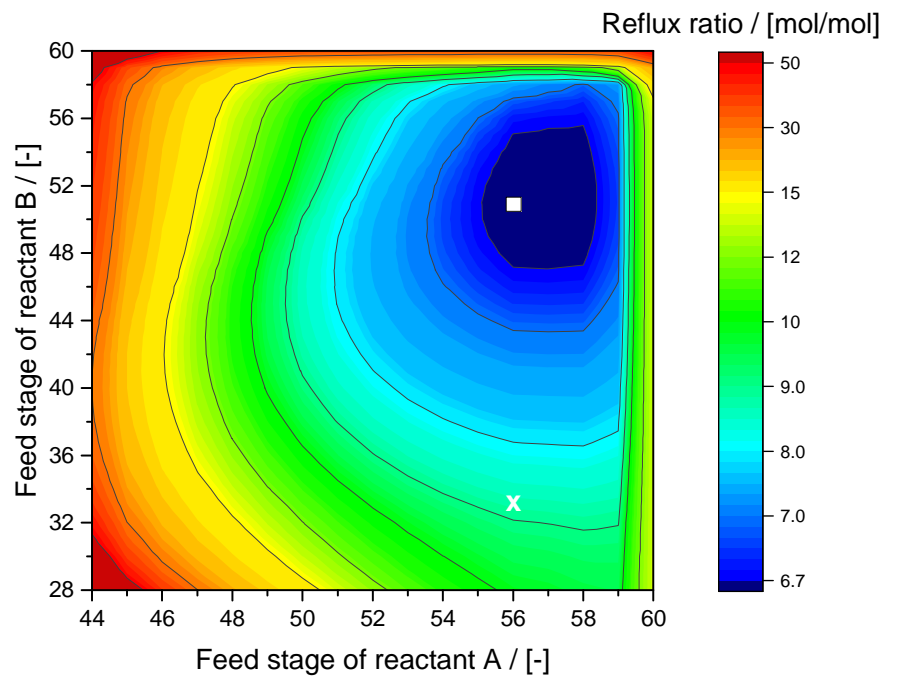

(c)

Figure 7. Varied feed locations of both reactants A and B and their corresponding RRs at $8 \quad \mathrm{~K}_{\mathrm{eq}}=1$ for (a) group $\mathrm{I}_{\mathrm{p}}$, (b) group $\mathrm{III}_{\mathrm{p}}$ and (c) group $\mathrm{III}_{\mathrm{r}}$. Cross and square indicate the base cases and the RD configurations with the most optimal feed locations, respectively. 


$$
T_{b, c}<T_{b, A}<T_{b, B}<T_{b, D}
$$

2

$$
T_{b, c}<T_{b, A}<T_{b, D}<T_{b, B}
$$

4

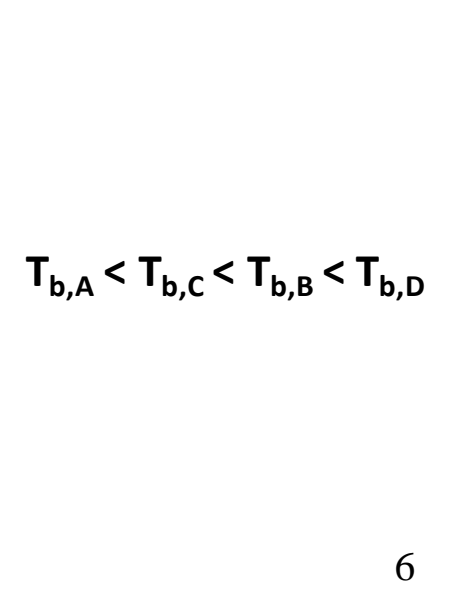

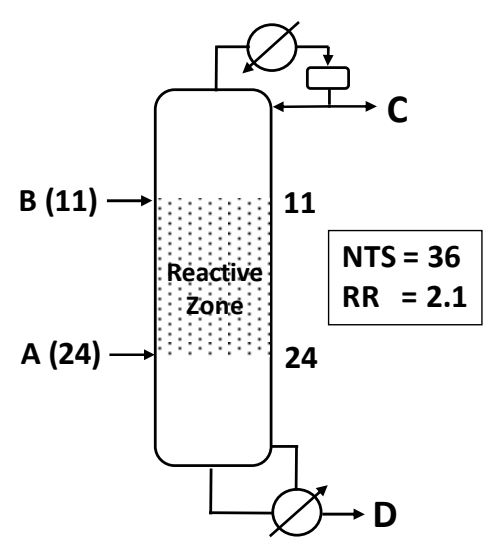

(a)

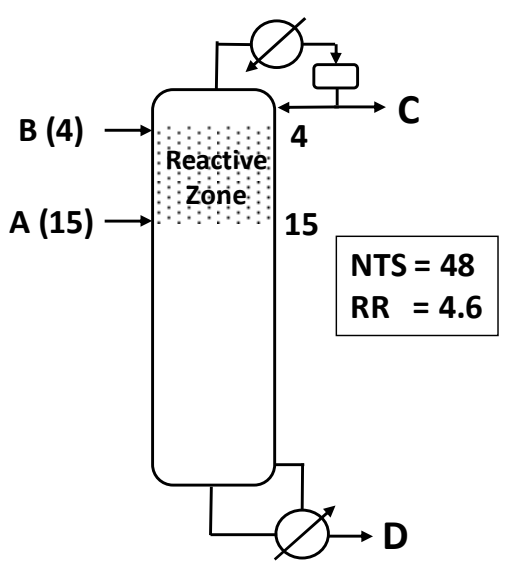

(c)

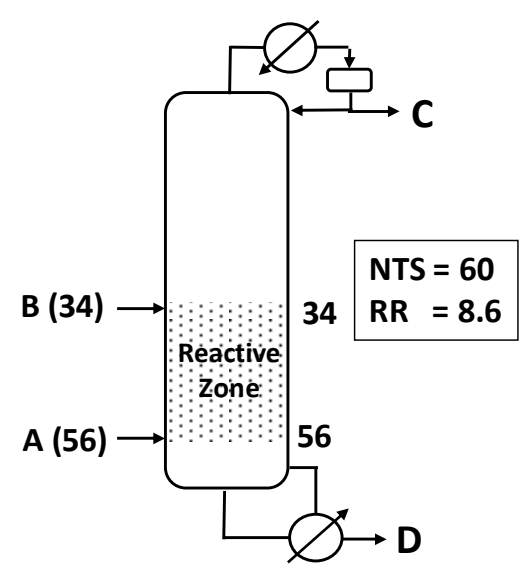

(e)

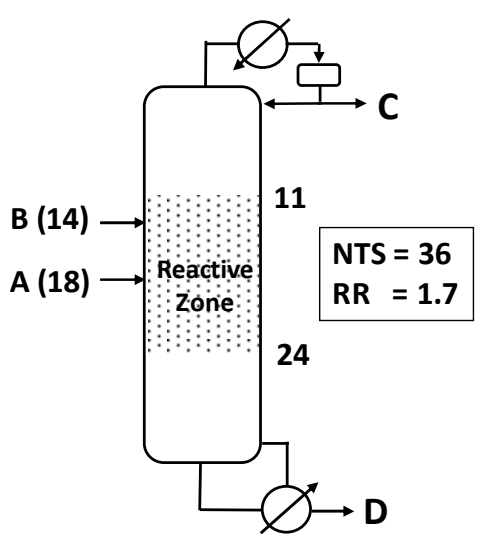

(b)

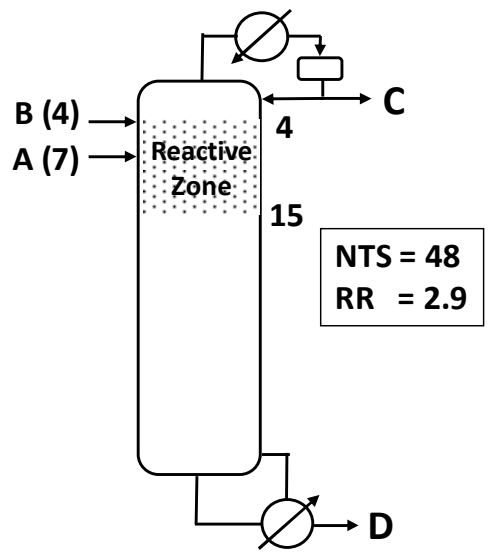

(d)

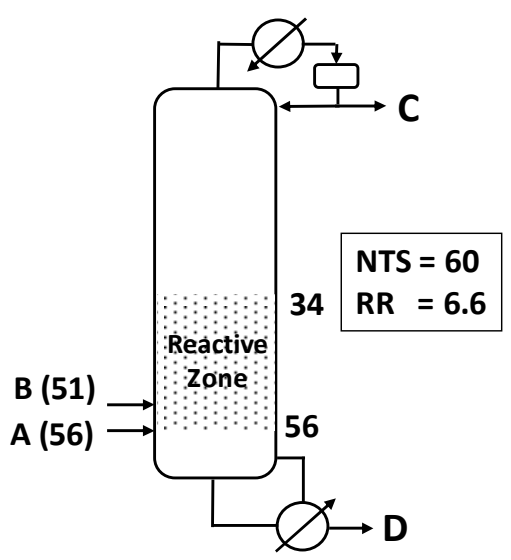

(f)

Figure 8. RD column schemes in case of fixed feed inlets at the top and the bottom parts of reactive zone for (a) group $\mathrm{I}_{\mathrm{p}}$, (c) group $\mathrm{III}_{\mathrm{p}}$, (e) group $\mathrm{III}_{\mathrm{r}}$ and in case of varied feed inlets to obtain the lowest RR possible for (b) group $\mathrm{I}_{\mathrm{p}}$, (d) group $\mathrm{III}_{\mathrm{p}}$, (f) group $\mathrm{III}_{\mathrm{r}}$. The presented numbers next to the column show the RD stages. All RD column configurations are at $\mathrm{NTS}=2 \cdot \mathrm{NTS}_{\min }$ in the applicability graph considering $\mathrm{K}_{\mathrm{eq}}=1$. 


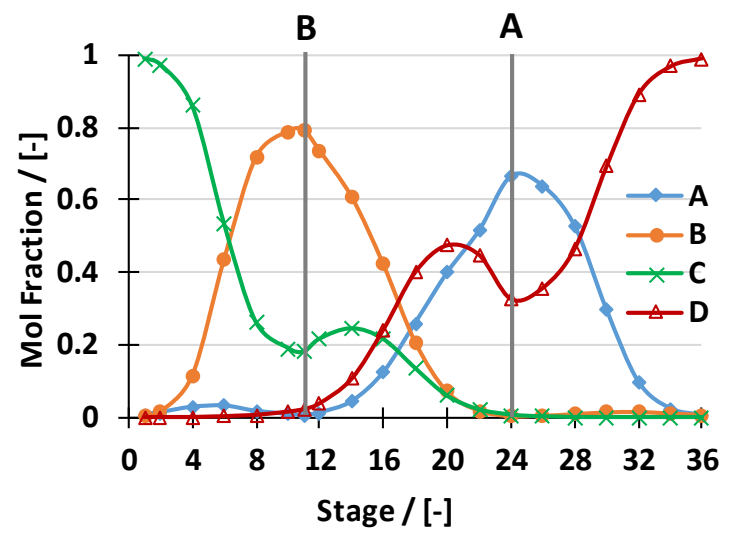

(a)

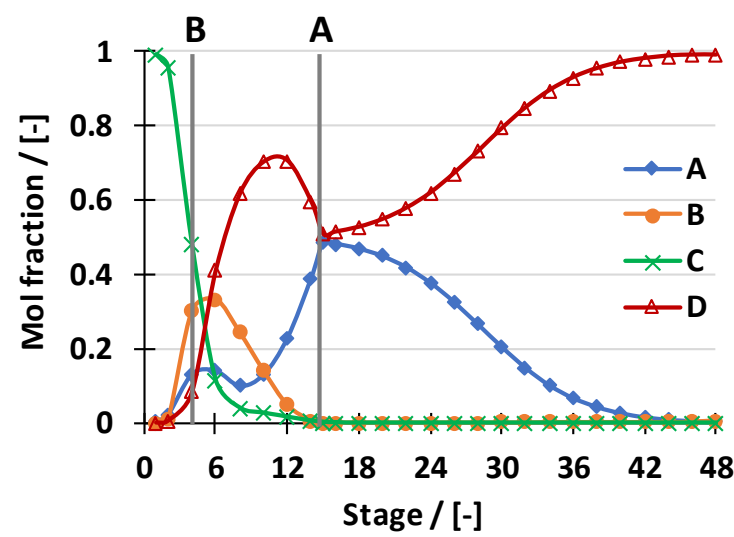

(c)

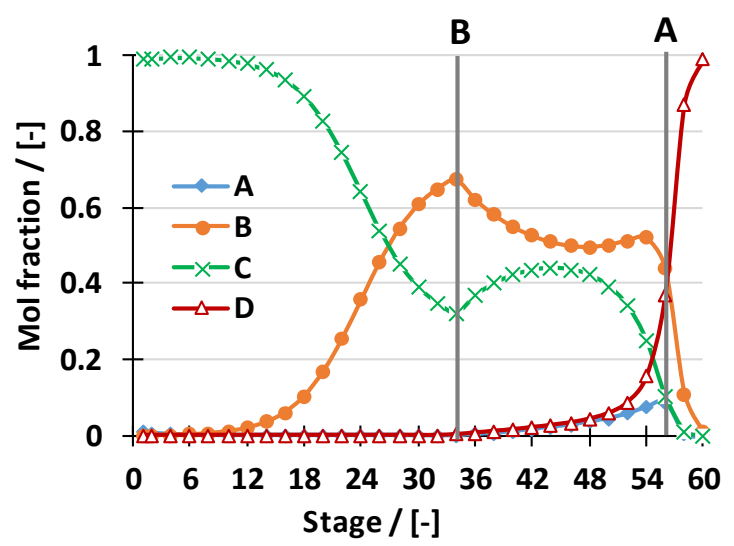

(e)

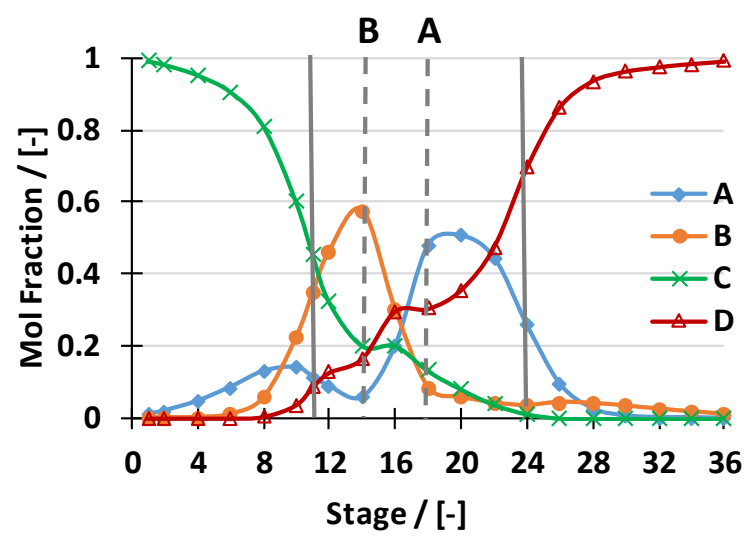

(b)

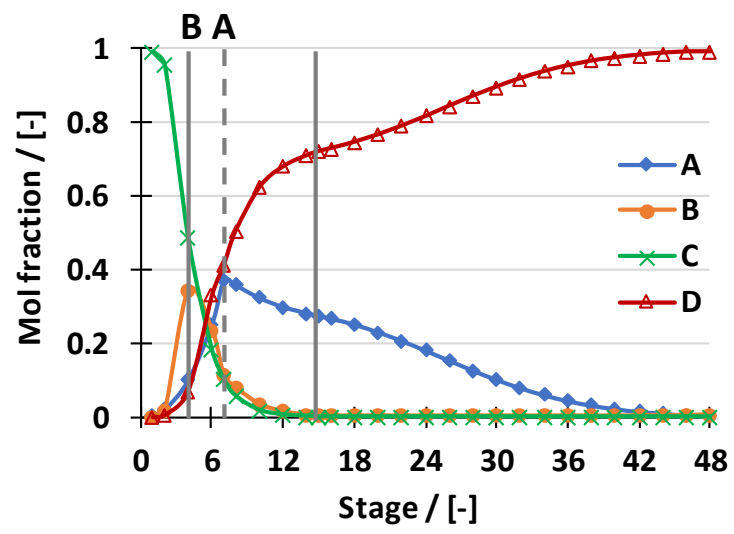

(d)

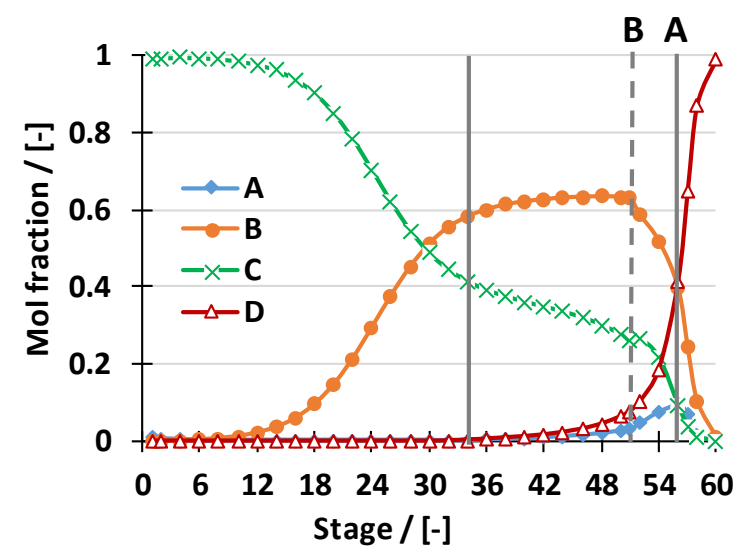

(f)

Figure 9. The composition profiles of RD column configurations in case of fixed feed inlets at the top and the bottom parts of reactive zone for (a) group $\mathrm{I}_{\mathrm{p}}$, (c) group $\mathrm{III}_{\mathrm{p}}$, (e) group III $_{\mathrm{r}}$ and in case of varied feed inlets to obtain the lowest RR possible for (b) group $I_{p}$, (d) group $\mathrm{III}_{\mathrm{p}}$, (f) group $\mathrm{III}_{\mathrm{r}}$. The vertical solid lines always show the top and the bottom parts of reactive zone, and also the feed inlets in (a), (c), (e). The vertical dash lines in (b), (d), (f) present the feed inlets. All RD column configurations are at NTS $=2 \cdot \mathrm{NTS}_{\min }$ in the applicability graph considering $\mathrm{K}_{\mathrm{eq}}=1$, and relative volatilities according to Table 1 . 